\title{
AS PROPAGANDAS DA REVISTA FEMININA (1914-1936): A INVENÇÃO DO MITO DA BELEZA
}

\section{THE ADVERTISEMENTS OF REVISTA FEMININA (1914-1936): THE INVENTION OF THE MYTH OF BEAUTY}

\author{
Ana Carolina Eiras Coelho Soares \\ Professora Adjunta do PPGH da Universidade Federal de Goiás \\ hanaakif@hotmail.com \\ Neide Célia Ferreira Barros \\ Especialista em História Cultural - Universidade Federal de Goiás \\ neidecelia@gmail.com
}

\begin{abstract}
RESUMO: O presente artigo trata do mercado de consumo que se desenvolveu no Brasil no fim do império e início da primeira República em torno da imensa valoração do corpo (limpo, saudável, branco e reprodutivo) da mulher como centro da sua identidade. A análise das publicidades da Revista Feminina, importante periódico brasileiro do início do século XX, a partir dos discursos publicitários permite compreender a construção do corpo feminino que, já no início do referido século, recebia um influxo de informações para talhar a mulher nos moldes ansiados pela sociedade e, ao mesmo tempo, ensinar a esta mulher como deveria ser, parecer e qual era seu papel nesse grupo. Dessa maneira, buscou-se entender a historicidade das representações sobre o corpo feminino e de que maneira as características a ele imputadas permanecem como heranças sociais de poder e cultura.
\end{abstract}

PALAVRAS CHAVES: Modernidade. Gênero. Beleza. Publicidade. Brasil República.

ABSTRACT: This Article comes to the consumer market that developed in Brazil at the end of empire and the beginning of the first Republic around the immense valuation of the body (clean, healthy, white and reproductive) of women as the center of their identity. The analysis of the advertisements of Revista Feminina, an important periodical of the early twentieth century, from the speeches advertisers to understand the construction of the female body which at the beginning of this century received an influx of information to whittle the woman longed to mold society while teaching this woman should be, and look what was his role in this group. In this way, sought to understand the historicity of representations of the female body so that the characteristics attributed to him remain as legacies of social power and culture.

KEYWORDS: Modernity. Gender. Beauty. Advertising. Brazil Republic.

\section{À guisa de introdução}

"Seja bela ou tenha pelo menos um rosto que lembre um templo e Seja leve como um resto de nuvem: mas que seja uma nuvem Com olhos e nádegas."

(Vinícius de Moraes) 
No ano de 2004 a fundação Itaú inaugurou na cidade de São Paulo uma exposição denominada "O preço da Sedução. Do espartilho ao Silicone" que trouxe objetos e obras de arte que representavam a beleza feminina, desde o final século XIX até o começo do século XXI. A mostra reuniu cerca de 129 obras entre pinturas, esculturas, instalações e fotografias a fim de evidenciar as mudanças dos padrões estéticos do corpo na cultura ocidental nesse período, principalmente no Brasil. Segundo os organizadores a "enorme receptividade do público deu a medida do interesse pelo tema." (MATTAR, 2004, p.1)

Um dos objetivos da exposição era demonstrar que a beleza faz parte de uma construção social. Assim, a curadora Denise Mattar citou que "ao longo da história e em culturas diferentes" muitos foram os métodos para obter o corpo desejado. Sendo estes desejos diferentes em diferentes momentos: "Já foi belo cobrir a pele de alvaiade, para tornala muito branca, ou passar horas no sol para bronzeá-la, alisar os cabelos com soda cáustica ou encrespa-los com enxofre." (MATTAR, 2004, p.1) Contudo, apesar de considerar que as expectativas de formas são criadas na cultura, a curadora da exposição ressaltou no texto do programa que "a cobrança da beleza da mulher é um fato - desde sempre". Pois segundo esta, a "beleza" é a principal "moeda para a mulher". (MATTAR, 2004, p. 3) Desta maneira, a partir da fala de Denise Mattar, parece consolidado a noção de naturalização do papel ao qual o feminino é incumbido por natureza, o de bela sedutora. Mesmo salientando que o tempo muda a expectativa de corpo, destaca também que desde sempre a mulher teve sua identidade relacionada a este corpo esperado. Ou seja, a beleza muda, mas a beleza é uma propriedade do feminino. Mais que isso, seu corpo é o centro de sua personalidade e sua principal - quiçá única - qualidade e oportunidade de poder.

Entendemos que o termo beleza utilizado refere-se, portanto, a um conceito ligado à ideia de corpo considerado adequado às formas ditadas pelo grupo social, e não à ampla concepção platônica de beleza como uma existência autônoma, distinta do suporte físico que a exprime, ou como concebe Vilém Flusser que afirma que o "belo, em sua essência seria uma espécie de abstração pura, dotado de uma plasticidade que pode estar presente em todo tipo de forma com a potencialidade de transcendê-la, tornado qualquer objeto digno e belo". (GARCIA, 2013, p.27)

Georges Vigarello demonstra em suas pesquisas que nem todas as culturas e tempos valoram ou valoravam o corpo como centro de uma identidade. (SANT'ANNA, 2000, p.1) 
Naomi Wolf (1992, p.16) afirma que na tribo Wodaabe da Nigéria, em oposição ao "mito" ocidental, a beleza está associada ao masculino. De acordo com a autora, os "homens do povo wodaabe passam horas juntos em complicadas sessões de maquiagem e competem" entre si requebrando os quadris no ímpeto de atrair as mulheres que detêm o poder econômico. A associação desta peculiar noção de beleza - corpo de acordo com as métricas sociais - ao feminino é uma invenção histórica, nos termos que propõe Durval Albuquerque Júnior (2007, p.20), ou seja, "uma dada ruptura, (...) um momento inaugural de uma prática, de algum costume, de alguma concepção, de algum evento humano."

Joan Scott em Gênero uma categoria útil à análise histórica trouxe à luz a ideia de que as masculinidades e feminilidades não são inatas aos humanos, mas sim aprendidas na cultura e constituem dimensões primárias de poder em tais sociedades. De tal modo, se tomarmos por base as perspectivas de Scott, será possível notar também que as formas de exercício do poder que tutelam socialmente a mulher são históricas, e do mesmo modo construídas nas relações sociais (1990, p.1-5) pois acontecem de maneira direta através de seu corpo, considerando sua principal identidade.

Desta maneira, pretendemos analisar as publicidades da Revista Feminina, importante periódico brasileiro do início do século XX para, a partir dos discursos publicitários, compreendermos a construção do corpo feminino que já no início do referido século recebia um influxo de informações para talhar a mulher aos moldes ansiados pela sociedade, e ao mesmo tempo, ensinar a esta mulher as normas adequadas socialmente, ou seja como ela deveria ser, parecer e qual era seu papel nesse grupo. Silvia Sasaki (2010, p.1) afirma que "as propagandas veiculadas em periódicos disseminam muito mais que as possibilidades de simples aquisição" e incuti "gostos, hábitos e discursos em seus leitores através das propagandas." Logo, compreendendo que os anúncios são também espaços de convencimento, procuramos entender os direcionamentos que as publicidades têm na construção dos corpos femininos.

Assim, a invenção do mito da naturalidade ganha contornos históricos. A sua relação entre o feminino e o corpo vigiado, ou seja, belo e sedutor, atende dentre tantos fatores, a um interesse econômico industrial. E tal indústria tem como matéria prima as insatisfações femininas tão bem introjetadas em espaços pedagógicos formais e não formais, bem como a revista feminina em questão. A mulher, nas publicidades pesquisadas reduz-se à capacidade de ser corpo, desejado e reprodutivo, do mesmo modo corpo perecível e desvalorizável, caso não tenha ou perca as formas e as métricas adequadas. 


\section{Beleza e saúde à venda nas páginas da modernidade}

Na primavera de 1914 chegou às bancas a primeira edição do jornal A Luta Moderna, que mais tarde viria se tornar a Revista Feminina, grande sucesso de público e vendagem que permaneceria sendo editada até o ano de 1936. (SOARES, 2010, p.2) Fundada por dona Virgilina de Souza Salles, importante senhora da elite paulista, a revista trazia conselhos do que era tido como comportamento ideal feminino. Trazendo questões como maternidade, cuidado com o lar e com os filhos, a revista conservou o status de mãe/mulher, porém também abriu espaço para falar sobre os novos tempos. Trouxe questões de lutas como voto, combate à violência, trabalho fora do lar e ensino superior para mulheres. E no meio de tudo isso, tentou inserir os preceitos de modernidade e higiene - que tanto circulavam pelo país em tal período - no ímpeto de ser uma leitura educativa. Contudo, mais do que simplesmente educar as mulheres da elite brasileira, especialmente paulista, a Revista Feminina vendeu. Vendeu primeiramente suas edições, que chegaram à cifra de vinte e cinco mil exemplares, mas principalmente vendeu publicidade e até mesmo produtos em suas páginas cuidadosamente coloridas e ilustradas. (GELLACIC, 2008, p.10-18)

O fim do século XIX e início do século XX trouxe ao Brasil uma série de novidades. O burburinho das cidades crescentes, que envolvidas em um processo de consolidação capitalista deixava de lado o patriarcalismo rural, em busca da modernidade profetizada pela Europa. A solidificação da burguesia transformava os hábitos e lentamente ia impondo um pensamento burguês, recheado de conceitos como higiene e eugenia pelas principais cidades brasileiras. E especialmente aumentava a circulação urbana, ainda que vigiada, das mulheres nos lugares públicos. (D’INCÃO, 2008, p.223-225)

Em meio a tais processos, onde a mulher ultrapassou o espaço do doméstico, iniciouse uma cultura para o cuidado com o corpo, o que de certa forma levou ao surgimento de um mercado específico para tal. Maria Izilda Santos de Matos (2010, p.1) fala que "desde 1850, os produtores de remédios e cosméticos eram os maiores anunciantes, assumindo grande influência, impacto e atingindo um grande público". Desta forma ao falar do impacto de tais anúncios esta autora revela que acima de tudo há um processo dinâmico nas publicidades, onde os desejos de corpos viram produtos e os produtos viram desejos de corpos. Assim, associar a parte mais importante da identidade feminina ao seu corpo - que é falível e sujeito 
à "desvalorização" causada pela implacável passagem do tempo e pelas mudanças possíveis dos padrões desejados - a coloca em modo de constante insegurança e incentiva o consumo de recursos para evitar que sua personalidade e seu reconhecimento social se escoem junto com a sua aparência.

Como anuncia Denise Mattar, em sua introdução à exposição de arte sobre os artifícios de beleza dos últimos séculos:

Para seduzir é preciso ser bela ou tornar-se bela, (...) o ritual inclui artifícios como os cosméticos - cremes, perfumes e maquiagem; os adornos penteados, jóias, flores, fitas, tatuagens, piercings; os trajes - roupas de baixo, vestidos, saias, blusas, calças; os acessórios - chapéus, bolsas, sapatos, leques, sombrinhas, entre outros. A sedução custa caro, e as mulheres sempre pagaram o preço sem discutir, chegando as vezes até ao ridículo. As armas do arsenal feminino variam de acordo com a beleza de cada época, da musa a top model, do espartilho ao silicone. (MATTAR, 2004, p.3)

A importância de tal mercado também pode ser percebida pelos anúncios da Revista Feminina. Já em 1920-22 nossa pesquisa aponta que cerca de 35\% das publicidades apresentadas mensalmente nas edições da revista eram direcionadas especificamente à modelagem do corpo, se apresentando como remédio ou cosmético, numa função múltipla de cuidar, tratar e embelezar. Nestes dados não estão inclusos a divulgação de objetos de adornos como jóias ou tecidos, e sim publicidades que prometiam o melhoramento do corpo em si. Outra porcentagem importante das publicidades se ligava à imagem da mulher cuidadora (publicidades de remédios para crianças, fortificantes e de itens para decoração do lar).

Contudo, o periódico oferecia também esporádicas propagandas aparentemente direcionadas ao público masculino como de charutos, companhia mecânicas e serviços de manutenção de carros. Assim, em um contexto onde a mulher não era incitada a tais atividades, entendemos que a revista propõe que existe um diálogo entre marido e esposa. Uma consideração importante é que a maior parte da publicidade direcionada à mulher é relativa ao cuidado e a modelação de seu corpo. Ainda que as atividades de cuidadora concentrem o maior espaço nas páginas publicitárias, essas são ligadas a diversas funções do cuidar. Desta forma consideramos que, mesmo em uma quantidade menor, o número dos produtos que se direcionam especificamente ao embelezamento acaba se tornando mais expressivo, por se direcionarem a uma única função: tornar a mulher bonita e saudável. 
Além das publicidades com grandes imagens nas páginas iniciais ou finais a Revista Feminina ainda mantinha uma página com pequenos "classificados" onde havia indicações de produtos, médicos, cabeleireiras e livros. Dentre tais produtos, um que sempre aparece em quase todas as edições é a Onichophagina, produto responsável pelo crescimento e fortalecimento das unhas, vendido através da Revista e provavelmente um dos produtos da Empreza Feminina Brasileira. Gisele Bischoff Gellacic afirma que:

Um fator muito inovador da Revista Feminina foi o de combinar a imprensa com um elaborado esquema comercial, o que provavelmente contribuiu para sua sustentação durante mais de vinte anos. A chamada Empreza Feminina Brasileira, que fabricava e comercializava produtos destinados à mulher como cremes para o rosto, tintura para o cabelo e livros de culinária. Podemos perceber o crescimento desta empresa ao longo dos anos, quando comparamos que no ano de 1916, a Revista possuía 2 produtos à venda, já no ano de 1925 possuía mais de 40 produtos. (2008, p.18)

A tintura Petalina (Imagem 1), um dos carros-chefes da Empreza é um claro exemplo de produto de grande destaque nas páginas da revista, e provavelmente de grande vendagem, uma vez que permanece sendo anunciado por muito tempo. Tal produto, que prometia "enegrecer os cabelos" aparecia em quase todas as publicações, algumas vezes em lugares de destaque, como única propaganda da página, como podemos ver a seguir.

\section{Imagem 1}

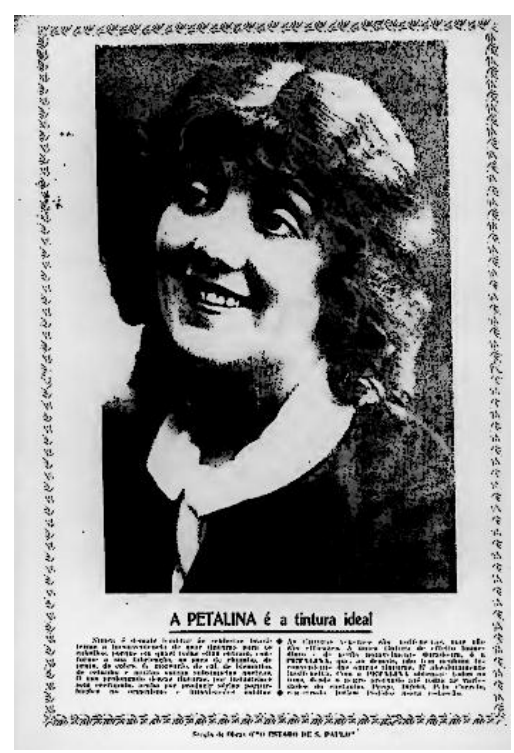

Fonte: Revista Feminina, 1920 
Grande parte dos produtos vendidos pela empresa da revista, como afirma Gellacic, se tratava de produtos de beleza. Na revista $\mathrm{n}^{\circ} 129$, do ano de 1925, dos 27 produtos vendidos pela Revista Feminina, anunciados em pequenas notas em duas páginas, ou seja, negociados pela empresa da família Souza Salles, 21 era de embelezamento. Dentre eles se destacavam os esmaltes, as tinturas de cabelo, os cremes de clareamento da pele e as águas de limpeza. Os demais produtos anunciados se tratavam normalmente de remédios para males de senhoras ou fortificantes. Desta maneira o discurso da beleza como um objetivo feminino movimentava, quem sabe até, sustentava a revista.

Isto era reafirmado através das figuras que ilustravam e salientavam a dicotomia bonito/feio, no intuito de persuadir o cliente a consumir o produto. A imagem abaixo, publicada na revista no ano de 1921, trouxe a oposição entre a beleza da imagem da mulher usuária do produto, em contraposição às demais, com uma aparência asquerosa, que sofrem de "sardas, pannos, espinhas e rugas". Nesta peça percebemos que os produtos polivalentes curavam não apenas os males da pele, mas também os sinais da idade, logo afirmando que beleza não é apenas saúde, mas também juventude. E a imagem de belo com seu oposto feio, torna mais nítida e persuasiva a mensagem. Tornando possível a compreensão do "belo/bom a todo sempre é desejado e o feio/mal a todo sempre é indesejado.” (GARCIA, 2013, p.26).

\section{Imagem 2}

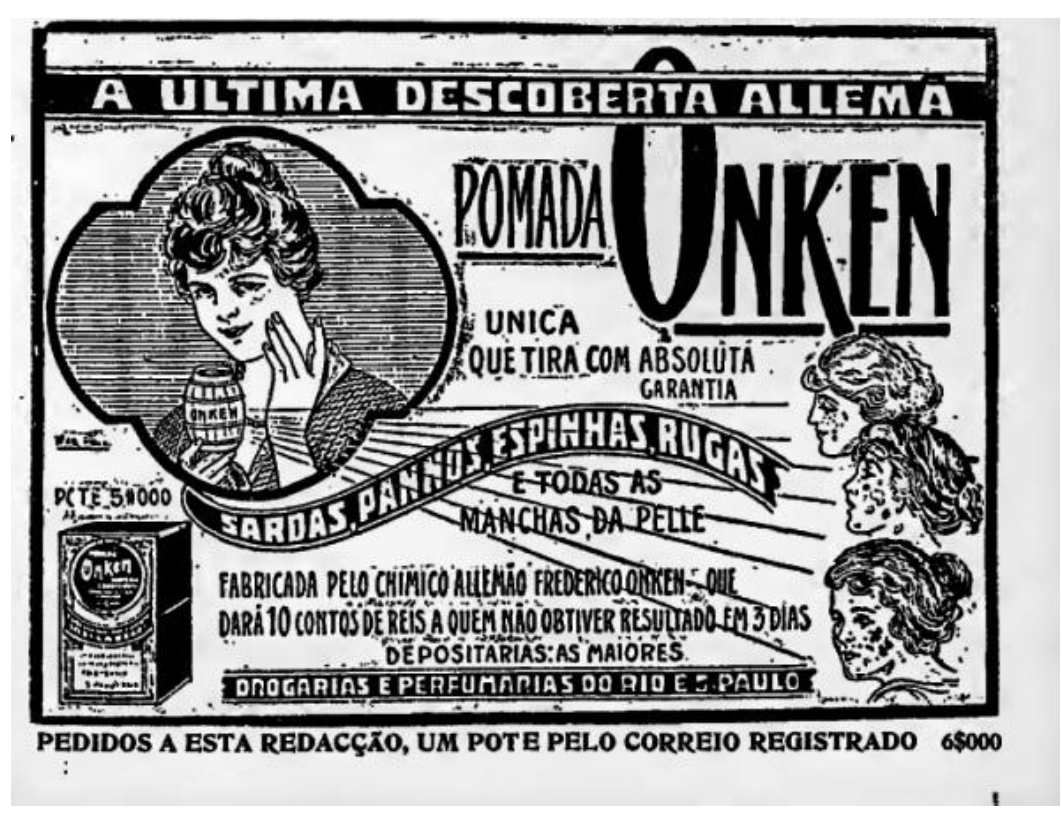

Fonte: Revista Feminina, 1921 
A série a "Arte da Belleza" publicado nos anos de 1920-21, mencionava diversas ideias a respeito de embelezamento reafirmando a concepção de que beleza é fruto de um exercício contínuo, uma arte que exige seu preço. Desta maneira, as falas se casavam com as intenções, em um processo múltiplo e dinâmico que pretendia educar ensinando os preceitos da modernidade higiênica, mas também visava se sustentar e obter sua lucratividade. Essa série publicada durante quatorze meses ensinava que ser bonita era consequência de esforço e disciplina, e que não se definia apenas pela forma natural do corpo, mas também pela forma aprendida como este se comportava. Todas as diversas instruções - algumas um tanto quanto estranhas aos olhos contemporâneos - se ligavam à oposição entre masculino e feminino, como se os gestos de um fossem considerados feios - inadequados - ao outro.

Assim, enquanto os homens têm seu poder na força e desempenho intelectual, financeiro e social à mulher foi ensinado que seu prestígio social, ou seja, "seu poder de fazerse ouvir, de ocupar um lugar junto dos homens (...) depende antes de mais nada de seu potencial de beleza, de sua aptidão por fazer-se bela" (SCHPUN, 1999, p.89), de modo que deve concentrar a maior parte de seus esforços e energias para ser bonita.

A série "A arte da belleza" não foi a única menção da revista sobre como deveria ser o corpo feminino adequado. Ao longo de inúmeras publicações apareciam crônicas, fábulas e narrativas que determinavam que a personalidade da mulher está intimamente ligada à sua aparência. Uma pequena nota, em uma de suas edições iniciais (dezembro de 1914) dizia:

\begin{abstract}
A baroneza de Stael dizia que de boa vontade daria metade de seu talento pelo "chame" e a gentileza physica. É bem provável que a maior parte das mulheres de gênio, que a natureza não favoreceu no ponto de vista da formosura plástica, não ache este preço em demasia exagerado. Aqui para nós, devemos tomar a vida como ella é, com suas injustiças e defeitos. Todas as mulheres sabem que o homem não procura nelas o gênio ou a intelligencia - o que sucede só em caso acidental - mas sim a belleza que o seduz $e$ o attrahe. Eis a razão porque a mulher tenta por todos os modos segurar a belleza que os anos vão delapidando; atenuar e modificar todos os defeitos physicos por artifícios e "maquillagem". (A luta moderna, Dezembro de 1914. Grifo nosso)
\end{abstract}

Nas edições seguintes a mesma revista apresentou a fala de Anna Rita Malheiros, que respondeu a pergunta lançada em um concurso cultural do periódico: "Qual deve ser o papel da mulher nas sociedades modernas?”. Malheiros, que na verdade era o pseudônimo do médico e literato Claudio de Souza, afirmou que a mulher devia afinar-se aos anseios 
intelectuais do marido, desenvolvendo leituras e atualizando-se dos acontecimentos, contudo o seu papel principal atendendo a "estethica moral e afectiva" era ser esmerada "mãe e a esposa". Portanto, eram estas duas suas funções primordiais. (Revista Feminina, Janeiro de 1915, p.11-12)

A mesma revista que afirmava que ser esposa era um papel fundamental para a mulher moderna, também afirmava que só era possível alcançar tal status através da beleza, pois como bem argumentava, gênio e inteligência não eram atrativos suficientes para arrebatar um bom marido. Portanto, de acordo com os argumentos presentes na Revista Feminina compensava muito mais trocar qualquer talento intelectual pela perfeição física, porque no final das contas um corpo belo era o único predicado que lhe valeria para alcançar o prestígio social. Destarte se dedicar a "Arte da Belleza", com investimento de tempo, dinheiro e disciplina provavelmente lhe traria melhores frutos do que a dedicação ao desenvolvimento de suas aptidões intelectivas.

Naomi Wolf afirma que o "Mito da Beleza", ou seja, esta ideia de que o principal atributo feminino vem da capacidade de adequar o corpo às expectativas sociais, e que sua identidade se liga fundamentalmente ao seu físico, é acima de tudo um discurso político de desempoderamento da mulher. Apesar deste se revestir de uma fala científica, dotada de argumentos biológicos - na qual se afirma que a beleza é um critério de seleção natural - tal discurso não passa de uma fala de opressão inventada nas sociedades contemporâneas. Wolf reforça que a beleza se tornou um "padrão monetário" a partir da Revolução Industrial, pois antes dela "como a família era uma unidade de produção e trabalho" a valoração da mulher se dava a partir da sua capacidade de contribuir nessa unidade. Ou seja, suas habilidades de “trabalho, sagacidade econômica, força física e fertilidade.”. (1992, p.17) Assim para Wolf, a ideia de que a beleza se liga à mulher por uma questão biológica, nada mais é que um discurso que envolve diversos interesses políticos e econômicos.

Embora muitas mulheres percebessem que sua atenção estava sendo focalizada dessa forma, poucas compreenderam totalmente como esse enfoque é meticulosamente político. Quando se atrai a atenção para as características físicas de líderes de mulheres, essas líderes podem ser repudiadas por serem bonitas demais ou feias demais. O resultado líquido é impedir que as mulheres se identifiquem com as questões. Se a mulher pública for estigmatizada como sendo "bonita", ela será uma ameaça, uma rival, ou simplesmente uma pessoa não muito séria. Se for criticada por ser "feia", qualquer mulher se arrisca a ser descrita com o mesmo adjetivo se se identificar com as ideias dela. As implicações políticas do fato de que 
nenhuma mulher ou grupo de mulheres, sejam elas donas-de-casa, prostitutas, astronautas, políticas ou feministas, podem sobreviver ilesos ao escrutínio devastador do mito da beleza, ainda não foram avaliadas por inteiro. Portanto, a tática de dividir para conquistar foi eficaz. Como a "beleza" acompanha a moda, e o mito determina que quando alguma coisa feminina amadurece ela sai de moda, a maturação do feminismo foi distorcida de forma grosseira porém eficaz na lente do mito. (WOLF, 1992, p.91)

A invenção do mito da beleza feminina começou a ser forjado a partir do século XIX, nos países que se industrializaram inicialmente, como um processo reacionário de contenção das mulheres, que se emancipavam gradualmente: “Assim que o valor básico da mulher não pôde mais ser definido pela encarnação da domesticidade virtuosa o mito da beleza redefiniu como a realização da beleza virtuosa" (WOLF, 1992, p.23)

Atendendo a um interesse político e econômico, o excesso de valoração do aspecto físico da mulher cria um mercado quase que inesgotável, que se alimenta da insegurança e cria uma ineficácia política nas mulheres, pois enquanto "ser belo é um valor, ser feio é um desvalor" (GARCIA, p.27, 2013), tendo de ser combatido a todo e qualquer custo. Com isso, se toda sua identidade se prende à importância da aparência exterior, não estar bela a torna menos mulher, logo menos autorizada. Desta forma sempre haverá um mercado crescente da beleza, pois esta mulher cuja presença depende das formas de seu corpo, estará consumindo a fim de evitar perder o seu valor maior enquanto pessoa. Comprando produtos, sejam eles remédios como no caso das leitoras da Revista Feminina, sejam cirurgias high-tech das musas Hollywoodianas, tudo se paga para adquirir, manter ou apurar a desejada forma descrita nos manuais da cultura que a cerca.

Naomi Wolf argumenta que à medida que as mulheres obtiveram liberdades ao longo do século XX, perderam por outro lado o controle sobre o próprio corpo através do mito da beleza: "Desde a Revolução Industrial, as mulheres ocidentais da classe média vêm sendo controladas tanto por ideais e estereótipos quanto por restrições de ordem material"(1992, p.8).

Surgiu uma nova classe de mulheres alfabetizadas e ociosas. Da submissão dessas mulheres à domesticidade forçada, dependia a evolução do capitalismo industrial. A maioria das nossas hipóteses sobre a forma pela qual as mulheres sempre pensaram na "beleza" remonta no máximo a 1830 , quando se consolidou o culto à domesticidade e inventou-se o código da beleza. (1992, p.18) 
Tais códigos de beleza se expandiram junto com o capitalismo. Nicolau Sevcenko afirma que a partir da segunda metade do século XIX este sistema econômico estendeu seus tentáculos a todas as partes do globo, chegando a países de economia agrícola como o Brasil, e assim reformulando conceitos e inserindo diversos novos hábitos. Modificando os costumes de higiene, beleza e comportamento, intensificados a partir da proclamação da República. (SEVCENKO, 1998, p.15-20)

A historiadora Mary Del Priore (2000, p.11) ressalta claramente estas mudanças quando afirma: "Diferentemente de nossas avós, não nos preocupamos mais em salvar nossas almas, mas em salvar nossos corpos da desgraça da rejeição social. Nosso tormento não é o fogo do inferno, mas a balança e o espelho.”

Os novos hábitos em nome da modernidade e da nação que se construía tinham como meta "sanear, remodelar e civilizar" (SANDES, 2002, p.27) interferindo na construção dos corpos, especialmente o feminino. Neste processo de educação e modernização que viria sustentar mercados e fortalecer novos conceitos de comportamento, a imprensa teve um papel de destaque. Raquel Discini de Campos afirma que o jornalismo deste período (anos 19201940) "não apenas alteravam o tempo e os fatos ocorridos, criando mesmo outro fato, mas também arquitetavam representações coletivas que (...) contribuíam para existência de condutas coletivas" $(2009, \mathrm{p} .19)$

Deste modo, a Revista Feminina, assim como os demais periódicos, de sua época tinha um forte papel de educar para os novos tempos. Aliada à criação de novos valores a revista contribuiu para a existência de um mercado específico para o cuidado do corpo, muito bem explorado e incentivado pela Empreza Feminina Brasileira. Tal como afirmam Paulo Poli Neto e Sandra Caponi “a supervalorização da aparência física é acompanhada pelo crescimento de uma medicina da beleza" (2007, p.569). Interessante pensar nas heranças culturais e sociais diretas de tais práticas, que hoje reforçam a indústria da aparência, voltada prioritariamente para o público feminino.

Desta forma, indo de encontro às ideias de Wolf, notamos que a Revista Feminina contribuiu para consolidar e difundir novos conceitos de mulher e beleza. E que sob os discursos de modernidade esta revista alimentou um mercado e ajudou a reformular o imaginário a respeito do feminino, onde a aparência se tornou o centro da personalidade da mulher. Vale aqui falar que consideramos a tese da reponsividade de Mikhail Bakhtin, que pronuncia que os leitores se apropriam dos textos, adotando-os ou rejeitando-os. 
(MAGALHÃES, 2006, p.2) e a fala de Robert Stam (2010, p.333) sobre a complexidade que compõe um veículo midiático onde membros e audiência podem criar pressões e resistências.

Todavia, mesmo entendendo que da produção da revista à recepção dos leitores há um complexo quadro de resistências e circulação de ideias, lembramos que os veículos difundem suas "tendências ideológicas" mesmo que a "dominação" não seja absoluta. Assim, a Revista Feminina (re)afirmou a ideia de beleza ligada à mulher, e junto com isso conquistou um mercado próprio.

Ao longo deste trabalho percebemos que desde o início do século passado - entre os anos 1910 e 1930 - já havia um mercado fortalecido no Brasil que sobrevivia da venda de produtos para a modulação do corpo da mulher. Junto a este a Revista Feminina não apenas divulgava publicidades, mas também mantinha uma própria empresa de produtos do gênero. Isso nos faz notar que a rentabilidade do consumo do belo não é uma questão apenas do nosso tempo - que arrecadou só no Brasil, em 2012 cerca de 40 bilhões de reais ${ }^{1}$ - mas faz parte de um processo que envolve interesses econômicos e políticos, chamado por Naomi Wolf de "mito da beleza". Para Wolf, a associação obcecada do feminino com o belo - próprio da nossa contemporaneidade - leva a mulher a um distanciamento emocional, político e financeiro, além de criar um sistema de repressão sexual e atende não apenas ao mercado da beleza, mas também cria um "novo imperativo de consumo e uma nova justificativa para a desigualdade econômica no mercado de trabalho". (WOLF, 1992, p.23)

Desta maneira, buscamos analisar as publicidades da Revista Feminina mostrando-as como parte da consolidação do mito mencionado por Wolf, salientando que tal periódico é significativo para entender a ideia de invenção do mito da beleza no Brasil, uma vez que a revista estudada traz vestígios de um período de transição, no qual se buscavam a modernização e a consolidação do Estado dentro dos moldes capitalistas de produção. As publicidades da Revista Feminina revelam as mudanças e adequações que perpassam toda a sociedade brasileira na transição industrial e urbana, especialmente para as mulheres, que ganhavam espaço público levando a necessidade de um mito repressor fundado na adequação do corpo. E por fim, indo de encontro à fala de Joan Scott, ao entender a ligação da beleza ao feminino como parte de uma invenção histórica e social de poder que permeiam as relações de gênero desnaturalizando os discursos sobre as feminilidades e as masculinidades.

\footnotetext{
1 Informativo do site UOL notícias. http://mais.uol.com.br/view/s70pk4i6az2h/2012-mercado-da-belezamovimentou-quase-40-bilhoes-de-reais-04024C993964E4994326?types=A\&> Acesso em 02/06/2013.
} 


\section{REFERÊNCIAS BIBLIOGRÁFICAS}

ALBUQUERQUE JUNIOR, Durval. História. A arte de inventar o passado. Bauru: Edusc, 2007.

CAMPOS, Raquel Discini de. Mulheres e Crianças na imprensa paulista (1920-1940). Educação e História. São Paulo: Ed. Unesp, 2009.

DEL PRIORI, Mary. Corpo a corpo com a mulher. Pequena historia das transformações do corpo feminino no Brasil. São Paulo: SENAC, 2000.

D’INCÃO, Maria Ângela. Mulher e família burguesa. In: DEL PRIORI, Mary. História das mulheres no Brasil. São Paulo: Ed. Unesp, 2008.

GARCIA, Eduardo Campos. O belo e o feio. Resquícios de um nazismo. Revista Filosofia, ano VII, n. 78, Jan-2013, p.24-31.

GELLACIC, Gisele Bischoff. Bonecas da moda. Um estudo sobre o corpo através da moda e da beleza. Revista Feminina 1915-1936. Dissertação de mestrado, São Paulo: Pontifícia Universidade Católica, 2008.

MAGALHÃES, Lucilha de Oliveira. Introdução ao pensamento de Bakhtin. Revista Locus, v.13. n.1, p.210-215, 2007.

MATTAR, Denise. O Preço da Sedução. Do espartilho ao silicone. São Paulo: Itau Cultural, 2004.

MATOS, Maria Izilda Santos de. Sorria: Mulher, publicidade e dentes. Anais Eletrônicos. Seminário Internacional Fazendo Gênero9: Diásporas, Diversidades, Deslocamentos. Florianópolis: Universidade Federal de Santa Catarina, 2010.

MORAES, Vinicius de. Receita de Mulher. Disponível em <http://www.viniciusdemoraes.com.br/site/article.php3?id_article=202> Consultado em Maio de 2013.

PERROT, Michelle. As mulheres ou os silêncios da história. Bauru-SP: Edusc, 2005.

POLI NETO, Paulo. CAPONI, Sandra. A medicalização da beleza. Revista Interface. Vol.11, n.23, Set/dez 2007, p.569-584.

RUSEN, Jorn. O desenvolvimento da competência narrativa na aprendizagem histórica: Uma hipótese ontogenética relativa a consciência moral. In: SCMIDTH, Maria Auxiliadora.

BARCA, Isabel. MARTINS, Estevão de Rezende. (org). Jorn Rüsen e o ensino de história. Curitiba: ed. UFPR, 2010. 
SANDES, Noé Freire. Nação, políticas de Saúde e identidade (1920-1960). Coleção Quíron. Goiânia: Ed. UFG, 2002.

SANT'ANNA, Denize Bernuzzi. O corpo inscrito na história: Imagens de um arquivo vivo. São Paulo: Projeto História, Nov/2000.

SASAKI, Silvia. Smoking Fetiche. As representações femininas nas propagandas de cigarro (1940-1960). Seminário Internacional Fazendo Gênero 9: Diásporas, Diversidades, Deslocamentos. - Florianópolis: Universidade Federal de Santa Catarina, 2010.

SCOTT, Joan. Gênero: Uma categoria útil de análise histórica. Revista Educação e Realidade, v.15, n.2, jul/dez, 1990.

SCHPUN, Monica Raisa. Beleza em jogo. Cultura física e comportamento em São Paulo nos anos 20. São Paulo: Boitempo, 1999

SEVCENKO, Nicolau. Introdução. In: História da vida privada no Brasil, Volume 3. São Paulo: Companhia das Letras, 1998.

SOARES, Ana Carolina Eiras Coelho. Femininos regulados, masculinos veiculados: um estudo histórico do código civil e da imprensa no início do século XX. Seminário Internacional Fazendo Gênero 9: Diásporas, Diversidades, Deslocamentos. - Florianópolis: Universidade Federal de Santa Catarina, 2010.

STAM, Robert. Bakhtin e a crítica midiática. In: RIBEIRO, Ana Paula Goulart. SACRAMENTO, Igor. (org). Mikhail Bakhtin: Linguagem, cultura e mídia. São Carlos: Pedro e João Editores, 2010.

UOL mais. Disponível em < http://mais.uol.com.br/view/s70pk4i6az2h/2012-mercado-dabeleza-movimentou-quase-40-bilhoes-de-reais-04024C993964E4994326?types=A\&>Acesso em $02 / 06 / 2013$.

VIGARELLO, Georges. História da beleza. O corpo e arte de se embelezar, do Renascimento aos dias de hoje. Rio de Janeiro: Ediouro, 2006.

WOLF, Naomi. O mito da beleza. Como as imagens da beleza são usadas contra as mulheres. Rio de Janeiro: Rocco, 1992.

\section{FONTES DOCUMENTAIS}

A Luta Moderna. Dezembro de 1914.Revista Feminina. Janeiro de 1915.

Revista Feminina. Janeiro à Dezembro de 1921.

Revista Feminina. Janeiro à Dezembro de 1922. 
Acervos da Revista Feminina Disponíveis em:

Arquivo Estadual de São Paulo. Online. Disponível em <http://www.arquivoestado.sp.gov.br/upload/revistas/>

Biblioteca da Universidade Estadual de São Paulo. Online. Disponível em $<$ http://www.delphos.biblioteca.unesp.br> 